\title{
Understanding a communicated thought
}

\author{
J. Adam Carter ${ }^{1}\left[\right.$ [ Emma C. Gordon ${ }^{1} \cdot$ J. P. Grodniewicz ${ }^{2}$
}

Received: 7 March 2020 / Accepted: 1 September 2020 / Published online: 17 September 2020

(c) The Author(s) 2020

\begin{abstract}
The goal of this paper is twofold. First, we argue that the understanding one has of a proposition or a propositional content of a representational vehicle is a species of what contemporary epistemologists characterise as objectual understanding. Second, we demonstrate that even though this type of understanding differs from linguistic understanding, in many instances of successful communication, these two types of understanding jointly contribute to understanding a communicated thought.
\end{abstract}

Keywords Propositional understanding · Linguistic understanding · Objectual understanding · Understanding and luck

\section{Introduction}

Grigory Perelman proved the Poincaré conjecture. As a competent English speaker, you understand what you have just read. You have read that Grigory Perelman proved

Author names are listed alphabetically and these authors contributed equally to this work.

$\triangle$ J. Adam Carter

adam.carter@glasgow.ac.uk

Emma C. Gordon

emma.gordon@glasgow.ac.uk

J. P. Grodniewicz

j.grodniewicz@gmail.com

1 COGITO, University of Glasgow, Glasgow, UK

2 LOGOS, University of Barcelona, Barcelona, Spain 
the Poincaré conjecture. We call this kind of understanding, however one would like to characterise it in detail, ${ }^{1}$ linguistic understanding.

Linguistic understanding of a given utterance differs from understanding of a proposition expressed by this utterance. ${ }^{2}$ To understand the proposition Grigory Perelman proved the Poincaré conjecture, it is not sufficient to recognize, that this is what utterances of the English sentence 'Grigory Perelman proved the Poincaré conjecture' express in certain contexts. Prima facie, it seems plausible that Fields Medal recipient Terence Tao has a rich understanding of the proposition Grigory Perelman proved the Poincaré conjecture, while a fourteen-year-old not particularly interested in mathematics - very minimal. Nevertheless, as competent English speakers, they would both agree that this is precisely what is said in the first sentence of the previous paragraph.

There is clearly an epistemic difference between understanding a proposition and mere linguistic understanding. What is it? Epistemologists of understanding have by and large been inclined to set this question aside. For example, according to Stephen Grimm (2011), epistemologists seek to uncover the nature of

understanding of the natural world (broadly understood), and little will be said about how-if at all-the approaches on offer here might relate, for example, to the kind of linguistic understanding we have of concepts or meanings... [because] the way in which we achieve understanding in these areas seems different enough that it deserves to be dealt with separately (2011, p. 84, our italics). ${ }^{3}$

We disagree. At least, we disagree with the thought that understanding what people tell us (broadly speaking) is interestingly unlike the kind of understanding we have of the natural world, epistemically speaking.

Here is the plan for the paper. In Sect. 2, we briefly outline some of the key epistemic features of what epistemologists call objectual understanding-e.g., the kind of understanding one might have of a subject matter, such as football or geometry, and how this is typically thought to differ from (mere) propositional knowledge possession. ${ }^{4}$ Next, we show that understanding a proposition is just a special case of objectual understanding, viz. the understanding one attains only when one grasps (in an appropriate way) the relations between the constituents of a body of information. In Sect. 4, we demonstrate how it is that understanding a proposition and linguistic understanding are distinct from one another. Nevertheless, the two types of understanding are closely related; as we argue in Sect. 5, they jointly, and indispensably, contribute to what we call understanding a communicated thought, an important species of understanding that is distinct from, but consists of, both.

\footnotetext{
1 We come back to this question in Sect. 4.

2 We take propositions to be whatever plays the role of contents or objects of attitudes (e.g., belief) and speech acts (e.g., assertion), and semantic values of utterances of sentences in context. We say more on this topic in Sect. 3.

3 Grimm uses the term "linguistic understanding" in a very broad sense in which it includes grasping concepts and understanding propositions as meanings of linguistic expressions. We devote Sect. 4 to argue that the types of understanding we have of propositions and of linguistic entities are distinct.

4 Though see Kelp (2016) for resistance to this orthodoxy.
} 


\section{The epistemology of objectual understanding}

A widely held view in mainstream epistemology is that objectual understanding is a richer cognitive good than mere propositional knowledge. ${ }^{5}$ Objectual understanding attributions take the form " $\mathrm{S}$ understands $\varphi$ " where $\varphi$ is (or, can be treated as) as subject matter. "Giles understands algebraic geometry" and "Darla understands football" are paradigmatic sorts of objectual understanding attributions; note that the relations between Giles and algebraic geometry and Darla and football (respectively) are relations between agents and, not explanations (as in the case of understandingwhy $)^{6}$ but objects - viz, bodies of information. The view that objectual understanding can be in some way reduced to knowing an aggregate of propositions is - unlike the corresponding view that understanding-why can be reduced to propositional knowledge—widely rejected, ${ }^{7}$ and there are three key reasons for this: the argument from luck, the argument from degrees, and the argument from regress. ${ }^{8}$

The argument from luck goes as follows: Gettier-style cases feature a kind of epistemic luck that is widely taken to be incompatible with propositional knowledge (Pritchard 2005, 2015). If (objectual) understanding is a species of propositional knowledge, we should be able to generate Gettier-style cases for objectual understanding. But we cannot. Therefore, objectual understanding is not a species of propositional knowledge. 9

To use Kvanvig's (2003) often-cited example here, suppose the subject matter under consideration is the "Comanche dominance of the southern plains of North America from the late seventeenth until the late nineteenth century" (2003, p. 197). A student checks out and reads a book from the library on this topic, retains the information and can answer relevant questions afterwards, to the extent that it is natural to attribute to her an understanding of the relevant subject matter. Here's the twist: while each statement in the book read by the student was true, the fact that this is so was the result of a random and fortuitous glitch at the printers, which by dumb luck corrected for all the mistakes. As a result, all the true beliefs formed by reading the book are only accidentally true (e.g. Gettiered). As Kvanvig sees it, this discovery should not lead us to withdraw the initial claim that the student understands the subject matter in question even though it should be enough to lead us to deny that the student possesses the relevant items of propositional knowledge. Accordingly, Kvanvig reasons, objectual

\footnotetext{
5 For instance, Grimm (2011), Elgin (2009), Zagzebski (2001), Greco (2014), Riggs (2003, 2009), Bengson and Moffett (2011) and Kvanvig (2017).

6 For a substantial discussion of understanding-why, see Hills (2016).

7 If explanatory understanding is reducible to propositional knowledge, then Khalifa's (2013) proposal stands to motivate an avenue for reducing objectual understanding to propositional knowledge by way of reducing objectual understanding to explanatory understanding.

8 Cf. Kvanvig (2013) for an argument to the effect that understanding, rather than knowledge, has the property of satisfying curiosity.

9 Zagzebski (2001) and Kvanvig (2003) were among the first to suggest that objectual understanding is (unlike propositional knowledge) compatible with Gettier-style epistemic luck.
} 
understanding is (unlike knowledge) compatible with Gettier-style luck, ${ }^{10}$ and thus, the former is not a species of the latter.

Variations on the argument from degrees have been widely defended (e.g., Kvanvig 2003; Pritchard 2009; Zagzebski 2001; Riggs 2003; Grimm 2012). The core reasoning goes as follows. Objectual understanding is gradient. Whenever one understands something, we can ask to what degree they understand it. Propositional knowledge is not gradient in this way. You either know something or you do not: two people can't know that something is true to different degrees. This is so even if the two knowers differ with respect to how well justified they are in believing the target proposition. ${ }^{11}$ But if objectual understanding is just a function of knowledge possession-viz., knowledge of a conjunction of propositions - understanding will not be gradient any more than propositional knowledge of a conjunction is gradient. Therefore, objectual understanding is not a species of propositional knowledge. ${ }^{12}$

Thirdly, the argument from regress proceeds as follows. If possessing objectual understanding is a matter of knowing propositions, then we should expect that, for any (understandable) subject matter (or body of information) $\varphi$, there are some $n$ propositions $p$ such that (i) $p_{1}, p_{2}, \ldots, p_{n}$ are parts of $\varphi$ and (ii) S's knowing these $n$ propositions suffices for S's understanding $\varphi$. However-and for reasons that parallel the kind of reasoning that features in Lewis Caroll's (1895) 'anti-intellectualist' regress $^{13}$ (cf., Ryle 1945) - it remains an open question, for any given number of $\varphi$-relevant propositions one knows (and for any further item of propositional knowledge one might add to what one already knows), whether one understands $\varphi$. Just as, per Carroll and Ryle, drawing an inference plausibly requires some kind of ability, so does understanding. ${ }^{14}$ As Kvanvig (2003, p. 192) remarks, one can know various items of information but "understanding is achieved only when [these] informational

\footnotetext{
10 As Pritchard (2009) has pointed out, Kvanvig's case becomes even more compelling if we add a twist to the details: suppose Kvanvig's case is modified so that it becomes a barn-façade-style case, where the relevant epistemic luck at play is environmental rather than intervening. To do this, just imagine the book is itself a book each proposition of which the author knew (and so, none of which is Gettierized). But, for the twist, now suppose that this book is surrounded on its shelf by books in the library with inaccurate accounts of the Comanche dominance of the American plains-placed there by a jokester (who overlooked only the genuine book picked by the student). While, à la barn façade cases, propositional knowledge is incompatible with environmental luck — viz., where the belief could easily have been false despite nothing actually going awry (compare: Russell's stopped clock case)—it would seem especially strange to deny that our student understands the Comanche dominance of the American plains simply because he could have easily read a misleading book. Cf. Grimm (2006) for a challenge to the view that understanding differs from knowledge in its resilience to epistemic luck.

11 See, however, Pavese (2017) for some resistance to this idea in the context of the relationship between knowing how and knowing that. For a more general rejection of this idea, see Hetherington's defence of epistemic graduatlism (e.g., Hetherington 2001, 2011, 2013). For criticism of Hetherington's gradualist position, see e.g., Ginet (2010), Leite (2006), and Faulkner (2003).

12 The degree constraint applies primarily to objectual understanding and is less obvious vis-à-vis explanatory understanding (i.e. understanding-why).

13 For some resistance to this line of argument, as well as to Ryle's variation on it in the case of know-how, see Pavese (2015).

14 Elgin (2009) makes a similar point in suggesting that possessing objectual understanding is not simply a matter of believing a long conjunction of relevant propositions.
} 
items are pieced together by the subject in question", ${ }^{15}$ and the mere possession of such information does not, as this line of argument goes, entail that one is either able or disposed to do this. (Just imagine, for example, a pupil who fails to understand geometry despite coming to know, via reliable testimony with no defeaters, a range of propositions about geometry that a trusted teacher tells him).

What does this ability involve? According to Riggs (2003, pp. 20-21) it involves seeing how the various parts of the understood subject matter 'hang together', something one does only if one 'grasps' the relevant relations between the propositions making up the subject matter. Thus, as Grimm (2014) puts it: to understand one must "be able to see or grasp how changes in some of these items will lead (or fail to lead) to changes in the others". ${ }^{16}$ The idea is that S understands $\varphi$ only if S grasps certain relationships between the relevant parts that constitute $\varphi$; Kvanvig and Grimm have referred to what specifically is grasped as coherence-making relations, though how to best characterise the grasping requirement remains an issue of some controversy. ${ }^{17}$

\section{Understanding of a proposition}

The matter of how to understand the "grasping" metaphor has been a central issue in work on understanding across disciplines. ${ }^{18}$ For one thing, the grasping metaphor features prominently in an issue at the intersection of epistemology, the philosophy of mind and cognitive science-specifically, with regard to what counts as grasping a concept. However, the question driving this debate can easily be rephrased as a

\footnotetext{
15 Our italics. The most natural potential rejoinder here by the proponent of knowledge reductivism about objectual understanding is difficult to spell out in a way such that it would demonstrate that propositional knowledge would plausibly suffice as a regress stopper. For example, suppose the proponent of knowledge reductivism insists that the work done by grasping, vis-à-vis piecing together the relevant relations between propositions, could be accomplished by learning new knowledge of facts, in particular, facts about how the relevant items of information about the subject matter hang together, e.g., in indicative, deductive and explanatory support relations. As has been discussed variously in the literature (see, e.g., Kelp 2016; Gordon 2017) such a proposal can then be countered-in a way that bears close semblance to the reasoning Ryle (1945) gives in his own twist on Carroll's original regress; see here also Stanley (2011) for discussion-by pointing out that this further propositional knowledge might well be disconnected from the perspective of the thinker, such that it would remain an open question whether the subject would understand the subject matter in question. The relevant comparison with Ryle's example is as follows: just as it is an open question whether a student who has memorized modus ponens knows how to draw the relevant inference (when the time comes), it remains an open question even if we stipulate that the student is furnished with additional testimonial knowledge about how to do so (see, though, Stanley 2011, Ch. 1 for criticism). It is beyond what we can do here to review further possible moves in the dialectic between knowledge reductivists and their critics about objectual understanding. For our purposes, we are advancing this line as one notable line of argument against knowledge reductivism that has been well established; we are also considering in this section two additional arguments, either of which would suffice for establishing that it is problematic to think of objectual understanding as secured by propositional knowledge. Thanks for a reviewer at Synthese for pressing us on this point. For one notable example to go beyond standard thinking about knowledge reductivism about understanding, in order to salvage a knowledge-based position, see Kelp (2016) and Gordon (2017) for critical discussion.

16 See here also Hills (2009) for a similar proposal.

17 For an alternative view, see Kelp (2015), according to whom the understanding-relevant relations between propositions are best characterised as basing relations.

18 For discussion, see Grimm (2011).
} 
question about concept possession ${ }^{19}$ as opposed to a question about grasping, (and understanding), per se. But what about the debate about how to characterize the epistemic relationship we have to a propositions and propositional contents we understand? Here things are more complicated.

Propositions play a number of central roles in our mental and social lives. They function as:

- Objects or contents of attitudes like belief, speech acts like assertion, and perhaps others in each category;

- (Partial) meanings of utterances of declarative sentences, and perhaps others;

- Referents of 'that'-clauses;

- (Primary?) bearers of truth and falsity, and the modalities of truth and falsity: necessity, possibility, probability (subjective or epistemic, objective or metaphysical);

- What gets assessed in determining the validity of arguments.

(Garcia-Carpintero and Jespersen 2019, p. 1210)

As we noted at the outset, it's typical of those working on the epistemology of objectual understanding to set the matter of what's involved in understanding propositions (viz., what play the above roles) aside as though what would be involved-epistemically - in such understanding is fundamentally different from what would be involved epistemically in understanding the 'natural world' (Grimm 2011). But why think this, exactly?

Let us come back to the example we presented briefly in the introduction. Terence Tao and a fourteen-year-old read an utterance of an English sentence "Grigory Perelman proved the Poincaré conjecture." As a result, they both entertain ${ }^{20}$ the proposition Grigory Perelman proved the Poincaré conjecture. Nevertheless, it is at least prima facie plausible that Terence Tao's epistemic relation to this proposition is somehow different than the fourteen-year-old's (just as Terence Tao's relation to geometric topology is different than the fourteen-year-old's). The difference plausibly lies in the fact that Tao has a rich degree of understanding of the discussed proposition (and the whole field of geometric topology). The fourteen-year-old, on the other hand, has a minimal or no understanding of either of these subject matters.

In this section, we would like to defend two theses:

Weaker thesis: the kind of understanding we aim to have of propositions is similar to the kind of understanding-as-grasping that contemporary epistemologists call objectual understanding.

Stronger thesis: the kind of understanding we aim to have of propositions is type-identical to the kind of understanding-as-grasping that contemporary epistemologists call objectual understanding.

We would like to keep our discussion as neutral as possible with regard to the vast and venerable debate about the nature of propositions. The only assumption we make

\footnotetext{
19 See here, for example, Bealer (1998), Boghossian (2003), Peacocke (1989), Millar (1994).

20 We use entertain here as an umbrella term for whatever type of cognitive attitude one has towards the proposition after comprehending an utterance of a sentence expressing this proposition. Importantly, we do not claim that entertaining is a sui generis kind of mental attitude.
} 
is that propositions are structured, i.e., that they "are complex entities, entities having parts or constituents, where the constituents are bound together in a certain way" (King 2019). ${ }^{21,22}$

A convincing argument suggesting that propositions (or at least propositional contents of mental attitudes) are complex and structured entities appeals to their productivity and systematicity. ${ }^{23}$ Propositional contents are productive because anyone with basic conceptual repertoire can, at least in principle, entertain infinitely many of them. If you can entertain a proposition that the chair stands next to the table, and you have a concept of SOFA, you can entertain a proposition that the sofa stands next to the table, etc. Propositional contents are systematic because “...our ability to entertain... one propositional content is intrinsically connected to our ability to entertain other... propositional contents, so that our ability to entertain the one automatically implies that we can entertain the others" (Duncan 2018, p. 353). If you can entertain the proposition that a chair stands next to the table you can, by the same token, entertain the proposition that the table stands next to the chair.

This said, let's return to the main question of this section: how should we characterise the epistemic relationship we have to a proposition we take ourselves to understand? We suggest that, given the assumption that propositions are structured, a (singular) propositional attitude relation is off the table; after all, if we assume (for reductio) that we understand a proposition $p$ just when we stand in some propositional attitude relation to $p$, we find ourselves left unavoidably with a remainder: namely, what epistemic relation do we have vis-à-vis the constituents of $p$ ? Recall that productivity and systematicity rationalise that we grasp $p$ by grasping the constituents of $p$ and relations obtaining between them.

In light of this worry, we might be tempted toward an obvious sort of improvement-specifically, we might suppose that we can preserve a propositional-attitude approach and (unlike the previous view considered) cover for the remainder that was the cognitive relationship we must bear to the constituents of $p$. The idea would be something like the following: $S$ understands $p$ just when $S$ (i) bears some propositional attitude relation to $p$; and (ii) bears some propositional attitude relations $r_{1} \ldots r_{n}$ to the constituents of $p$.

An initial reaction here is to consider whether (ii) on this amended view would make (i) redundant. But ultimately, this doesn't much matter. The problem with the

\footnotetext{
21 In fact, our account of understanding of a proposition does not require any substantive metaphysical commitment to the "hidden natures" of propositions. It is compatible with deflationary views about propositions according to which either propositions themselves are not structured but they exist only as represented by structured representational vehicles (Garcia-Carpintero ms, p. 3) or "propositions are abstractions from (possible) mental state tokens that represent exactly the same" (Grzankowski and Buchanan 2019, p. 3160) and thus "inherit" the structure from these tokens. If representational vehicles but not propositions are structured, our account would be more precisely characterized as an account of understanding a propositional content of a vehicle. Everything we'll say can be stated by assuming this more deflationary stance.

22 More concessively still, we commit ourselves neither to a view that propositions are mind-independent entities (such as facts) nor to its negation (see, e.g., Collins 2018).

23 Again, it might be the case that only representational vehicles but not propositions are structured and, therefore, that systematicity and productivity should be explained by appeal to the features of vehicles, not propositions (Garcia-Carpintero ms).
} 
amended view is that there is no suitable way to fill in the details that will not lead the amended view to collapse into the aggregate view we considered in Sect. 2.

Recall that a fundamental problem for the aggregate view (vis-à-vis objectual understanding in epistemology) highlighted the sense in which objectual understanding appears to have a grasping condition as a necessary condition, and further, that such a condition (as per the regress problem) will not plausibly be satisfied simply by requiring that the agent know an appropriate number of propositions. The subject should also grasp the way in which the constituents of the subject matter "hang together." In the case of propositions it is relatively easy to fill in the details of the relevant grasping condition: grasping the way in which constituents of propositions "hang together" is just grasping the ways in which these proposition are structured, i.e., what are the relations relating their constituents. ${ }^{24}$

From here it's not hard to see that understanding a proposition is looking quite a bit like the kind of understanding epistemologists call objectual understanding. Even more, as we'll see, understanding of a proposition seems to be compatible with Gettierstyle cases that serve to undermine propositional knowledge.

Let's consider a case structurally similar to Kvanvig's (2003) library book case (Sect. 2). Suppose Alex is studying for a biology exam. A disgruntled employee at a company that makes the biology textbooks that Alex's class is using has tampered with the chapter on the structure and function of the cell, switching around some of the information. Alex, fortunately, grabs a book in which the disgruntled employee attempted to mix the definitions around but accidentally mixed them back in the original order, leaving the book that Alex grabs with correct descriptions of the elements of a cell. Alex's acquisition of the series of concepts (including NUCLEUS, CYTOPLASM, and MITOCHONDRION) is thus unsafe. Suppose that Alex studies the textbook carefully and is able to use these previously unfamiliar concepts to entertain propositions about cell structure. Moreover, if she hears an utterance of the sentence "Mitochondria contain no DNA" she can tell that the proposition expressed by this sentence is false, just as she can tell that the propositions expressed by the following sentences are true:

(1) Cytoplasm is enclosed by the cell membrane.

(2) Eukaryotic cells contain membrane-bound nuclei.

(3) Mitochondria produce most of the cell energy supply.

In short, and in a familiar sort of way, Alex has come (thanks to her biology textbook) to understand propositions expressed by utterances of sentences (1-3), even though the

\footnotetext{
24 Our story fits particularly well with a solution to the so called problem of the Unity of propositions offered by Eklund (2019) (for an exhaustive discussion of the problem see Gaskin 2008). Here's the problem: "How can there be this complex, the proposition, made up of its constituents, as opposed to merely (the collection of) the constituents themselves?" (Eklund 2019, p. 1236). A somehow classical worry is that the problem cannot be solved without falling into a vicious constitution regress. Let's take the proposition that $a$ is $F$. We might assume that it has two constituents: $a$ and $F$. But what is the difference between this proposition and a mere collection of $a$ and $F$ ? We have to say that in the proposition $a$ instantiates $F$ and thus that the proposition has a further constituent: the instantiation relation $R$. But in this case, what is the difference between this proposition and a mere collection of: $a, F$, and $R$ ? etc. Eklund's solution to this problem is to take the relation relating the constituents as primitive and not as a further constituent of the proposition: "what accounts for the constituents being combined into the unity they are is how they are related. What would the remaining worry be?" (Eklund 2019, p. 1244).
} 
unsafe acquisition of the relevant information undermines her would-be propositional knowledge of the definitions of constituents of the propositions expressed by (1-3).

Taking stock then, understanding of a proposition is, like the kind of objectual understanding that features in mainstream epistemology, (i) not reducible simply to the possession of a propositional attitude or propositional attitudes; (ii) has a grasping condition as a necessary condition; (iii) is compatible with knowledge-undermining epistemic luck. This concludes our argument for the Weaker thesis.

Can we go further and establish the Stronger thesis as well? If the stronger thesis is right, then understanding a proposition involves a kind of apprehension of the way the propositional constituents stand in relation to each other that is akin to the way understanding a body of information or a subject matter (e.g., algebraic geometry) involves a kind of apprehension of how the facts constituting this subject matter stand in relation to each other. Here the degree-based ex-ante constraint on objectual understanding noted in Sect. 2 is relevant. If it turns out that, for example, scientific theories, but not propositions, can be understood to greater or lesser degrees, this would surely count against the Stronger thesis.

As Riggs (2009, p. 7) notes "the amount of information present in someone's [objectual] understanding can vary:" 25 this will be the case, for instance, when we compare the understanding of a housefire possessed by a novice fireman as opposed to the understanding of a housefire possessed by an expert in exothermal reactions. ${ }^{26}$ In this respect, objectual understanding can vary along what we might call the information dimension. But the degrees of understanding possessed by two individuals might also diverge along what we'll call the action dimension. As Elgin (2009) notes: "the student who understands geometry can do more with it than the student who just knows all the axioms, the main theorems and their derivations." Stronger thesis (that understanding a proposition is a special case of objectual understanding) predicts, then, that for two individuals, A and B, A's understanding of some proposition $p$ should be able, in principle, to diverge from B's understanding of $p$ along both the informational and action dimensions.

Each of these points can be made rather straightforwardly. Firstly, the point about informational variance: consider that Terence Tao, as well as most of his first-year UCLA students, understand the proposition Grigory Perelman proved the Poincaré conjecture. Suppose a first-year student at UCLA, Johnny, knows the following things: that the Poincare conjecture was a problem in geometric topology that's usually illustrated by wrapping a string around a three dimensional object, and that proving the conjecture involved the application of a mathematical method called the Ricci Flow. ${ }^{27}$ All of this information was gleaned by Johnny (who is only beginning his maths degree) from an article in the New Yorker, written for a general audience. ${ }^{28}$

While Terence Tao and Johnny both understand Grigory Perelman proved the Poincaré conjecture, Terence is in a much better position to see how the constituents

\footnotetext{
25 Our italics.

26 See Carter (2017) for a more detailed analysis of this case.

27 See Perelman (2002). For an overview of the Ricci Flow, developed by Richard Hamilton, and its applications to the Poincaré conjecture, see Chow et al. (2006).

28 Nasar and Gruber (2006). Manifold Destiny, The New Yorker. August, 28, 44-57.
} 
of this proposition hang together; (after all, Terence, unlike Johnny, has the information necessary to appreciate a more specific sort of thing that would be involved in developing a proof of the Poincaré conjecture). Johnny's comparatively impoverished understanding of the proposition is betrayed by the fact that the information he possesses, and which bears on his understanding the proposition, gives him a significantly less rich picture of the subject matter of the proposition Grigory Perelman proved the Poincaré conjecture.

Not only can the understanding of a proposition (like understanding a body of information) two individuals possess diverge along an informational dimension (as we saw here) but it can do so as well along what we called the action dimension. Just as, à la Elgin (2009), understanding geometry allows one to do more with it than can one who merely knows axioms, main theorems and their derivations, Terence Tao can do more with his understanding of Grigory Perelman proved the Poincaré conjecture than Johnny can. Terence's, but not Johnny's, understanding of the proposition that Grigory Perelman proved the Poincaré conjecture includes items of information A, B, and $\mathrm{C}$, where $\mathrm{A}, \mathrm{B}$, and $\mathrm{C}$ are pieces of information about what Perelman must have proved to have proven the Poincaré conjecture. Terence, but not Johnny, can use A, $\mathrm{B}$ and $\mathrm{C}$ as premises in his practical reasoning, conditioned on his understanding that Grigory Perelman proved the Poincaré conjecture.

In yet another instance, then, objectual understanding and understanding of a proposition fail to come apart. This concludes our argument for the Stronger thesis: the kind of understanding we aim to have of propositions is type-identical to the kind of understanding-as-grasping that contemporary epistemologists call objectual understanding.

\section{Linguistic understanding versus understanding of a proposition}

Since one of the main roles of propositions is "to be the meanings of sentences (in context), or at least the contents expressible by sentences" (Collins 2018, p. 3) it is fairly easy to confuse the type of understanding relation we have to propositions with what is commonly discussed in philosophy of language under the label linguistic understanding. These two types of understanding are, however, importantly different.

Some popular recent theories identify linguistic understanding of an utterance expressing $p$ with: (i) knowledge that the speaker said that $p$ (Evans 1982, p. 311; Heck 1995, p. 84), (ii) "conscious awareness" (Hunter 1998, p. 560) or "quasi-perception" (Fricker 2003, p. 341) that the speaker said that p, (iii) a belief that $p$ (Millikan 2004, p. 121; cf., Mandelbaum 2014), or (iv) a state of entertaining the content $p$ (Longworth 2018, p. 822). ${ }^{29}$

\footnotetext{
29 It is not our goal in this paper to discuss and assess these views. Even if neither of them offers the accurate characterization of the phenomenon of linguistic understanding, they are all on the right track and thus sufficient for our purposes. For a detailed discussion of the limitations of these views and an alternative proposal see Grodniewicz (ms, 2020).
} 
What is common to all these views is that they characterise linguistic understanding as a mental state through which the hearer ${ }^{30}$ represents the content of a linguistic utterance. ${ }^{31}$ An ability to understand an utterance is thus an ability to recognize what is being said or what is the meaning of a given utterance of a sentence in a language one knows. In the case of assertoric utterances, it is an ability to recognize what proposition was expressed through a given utterance. ${ }^{32}$

It is, thus, not difficult to demonstrate the difference between linguistic understanding and understanding of a proposition. Let's return again to our example of the proposition Grigory Perelman proved the Poincaré conjecture ( $p)$. This proposition can be expressed by utterances of sentences of different languages, in particular by an utterance of an English sentence (EN) and a Polish sentence (PL).

(EN) Grigory Perelman proved the Poincaré conjecture.

(PL) Grigorij Perelman udowodnił hipotezę Poincarégo.

To demonstrate that understanding a proposition and linguistic understanding are different phenomena, we will use a comparison class of four protagonists: Terence Tao, ${ }^{33}$ a monolingual English fourteen-year-old not particularly interested in mathematics, a monolingual Polish mathematician specializing in geometric topology, and a monolingual Polish fourteen-year-old not particularly interested in mathematics.

As we argued in the previous section, both Tao and the Polish topologist understand p. They grasp and can explain what the proof would require, what light it sheds on various related problems in topology, etc. At the same time, Tao lacks linguistic understanding of (PL) while the monolingual Polish mathematician lacks linguistic understanding of (EN). Upon hearing utterances of respective sentences in languages they do not speak, they would not realise that what has been just said was $p$.

The situation is different in the case of monolingual teenagers. Let's take as an example the monolingual English teenager, Emily. Emily is capable of linguistic understanding of (EN) but incapable of linguistic understanding of (PL). Utterances of (PL) would sound to her like an incomprehensible babble. Even if she were able to guess that what she heard was an utterance of a sentence in a foreign language (as opposed to, say, gibberish), she would have problems detecting word boundaries, not to mention retrieving meanings of the words uttered or for that matter the whole utterance. Additionally, lacking any competence with geometric topology, Emily has no (or only minimal) understanding of $p$. Nonetheless, upon hearing an utterance of (EN), she recognises that what has been said was that one Grigory Perelman (whoever that was)

\footnotetext{
${ }_{30}$ For convenience, in most our examples we will focus on cases of hearing and linguistic understanding of speech. All that we say is mutatis mutandis applicable to linguistic understanding of written word, sign languages such as ASL, etc.

31 The content is represented either directly, i.e., simply as $p$ (Longworth 2018; Millikan 2004) or indirectly, i.e., as said by a given speaker (Evans 1982; Heck 1995; Hunter 1998; Fricker 2003).

32 Crucially, the minimal condition on linguistic understanding is stronger than mere recognition of a linguistic form or recognition of an utterance of a sentence in a given language as an utterance of a sentence in this language. One can, for example, recognize utterances of French sentences (i.e., they can tell that someone speaks French) without recognizing what is being said (i.e., without linguistic understanding of this utterances).

33 We assume that Terence Tao does not speak Polish. If he does, let us think instead about Tao's counterpart (Tao-minus-Polish) who doesn't.
} 
proved (whatever that takes) something called "Poincaré conjecture." Obviously, if she did not hear about Poincaré before, she would not recognise his name in the sentence. She might take "poincare" to be the proper name of the conjecture or, if this is the first time she encounters the concept of CONJECTURE, she could have even falsely assume that what Perelman proved was something called "Poincareconjecture." Nevertheless, she could later on use this information to start reading about the mysterious things she has heard about and soon learn a lot about Perelman, Poincaré, and geometric topology. After some time of devoted studies she could acquire a rich understanding of $p$ and the whole field of topology, possibly becoming one of Tao's most promising students.

To sum up. We demonstrated that it is possible to understand a proposition while being unable to linguistically understand utterances of sentences of a given language which express this proposition. It is also possible to linguistically understand utterances of sentences of a given language which express a proposition but fail to understand (or have only a very minimal understanding of) this proposition. This concludes our argument for the divergence between linguistic understanding and understanding of a proposition.

\section{Understanding a communicated thought}

In Sect. 3 we have argued that the type of understanding we have of propositions is just a special case of objectual understanding, and in the previous section, that it differs importantly from linguistic understanding. Nevertheless, the fact that these two types of understanding differ does not mean that they do not often co-occur. In fact, cases in which they co-occur are particularly interesting from the point of view of our successful and fruitful communication. ${ }^{34}$ Arguably, interlocutors communicate most effectively when they not only understand the linguistic expressions used by each other but also understand the things being said, i.e., how the propositions expressed represent the world. We call this understanding a communicated thought. ${ }^{35}$

If $u$ is an utterance of a sentence in a given language, and $p$ is the proposition expressed by $u$ in a given context:

Understanding a communicated thought requires:

a) linguistic understanding of $u$, and

b) (some level of $)^{36}$ understanding of $p$

\footnotetext{
34 We do not pretend that we provide here sufficient or even necessary conditions for communicative success. All we say is that the type of understanding which we characterize below is among the important factors contributing to communicative success (at least in some situations).

35 The phenomenon we characterize below could be more precisely called understanding of a thought as communicated through a given utterance. As we have demonstrated above, one could understand a communicated thought (e.g., $p$ ) but not as communicated through a given utterance [compare Tao's understanding of $p$ as expressed by (EN) but not (PL)]. The more accurate name is, however, quite a mouthful, so we will stick to the shorter version: understanding a communicated thought.

36 As we argued in Sect. 3, understanding a proposition, just like other kinds of objectual understanding, is a gradable matter.
} 
It's easy to apply this template account to the cases of our protagonists from the previous sections. Our $u$ will, again, be either (EN) or (PL), and our $p$ will be Grigory Perelman proved the Poincaré Conjecture. Tao will have rich understanding of the communicated thought if he hears (EN). He has linguistic understanding of (EN) and rich understanding of the proposition $p$. However, despite his deep understanding of $p$, Tao will not understand the communicated thought if he hears (PL), because he does not understand Polish. As we see, the first way in which one may fail to understand the communicated thought is by failing to understand the utterance through which a given thought was communicated.

There is, obviously, another way in which one might fail to understand the communicated thought. It is demonstrated by the example of the English speaking teenager, Emily. Despite her linguistic understanding of (EN), Emily barely understands the thought communicated through the use of $(\mathrm{EN})$ because she barely understands proposition $p$.

While arguing for the Stronger thesis in Sect. 3, we were comparing Tao's rich understanding of $p$ with his first-year student's (Johnny's) understanding of the same proposition. Our definition accounts for the fact that Johnny's epistemic standing towards $p$ as communicated through an utterance of (EN) is different to both Tao's as well as Emily's. Unlike Emily, Johnny has considerable understanding of the thought communicated through the use of (EN) because he has a considerable degree of understanding of $p$. Nevertheless, his understanding of a communicated thought is not as rich as Tao's because his understanding of the proposition $p$ is not as rich as Tao's. Since, as we demonstrated in Sect. 3, the type of understanding we have of propositions is gradable, and since it contributes to the understanding of the communicated thought, the understanding of the communicated thought is itself a gradable matter.

\section{Concluding remarks}

The goal of this paper was twofold. First, we argued that the understanding one has of a proposition or a propositional content of a representational vehicle is a type of what contemporary epistemologists characterize as objectual understanding. Second, we demonstrated that even though this type of understanding differs from linguistic understanding, in many instances of successful communication these two types of understanding jointly contribute to understanding a communicated thought. At the same time, we think that our discussion makes a case for a closer collaboration between philosophers interested in communication (linguistic communication in particular) and epistemologists. It is through paying attention to both these research fields at the same time that we will be able to tackle the knotty and multidimensional problem of understanding in human interactions.

Acknowledgements J.P. Grodniewicz would like to thank Manolo García-Carpintero for helpful comments and suggestions. Grodniewicz's research was funded by the DGI, Spanish Government, research project FFI2016-80588-R.

Open Access This article is licensed under a Creative Commons Attribution 4.0 International License, which permits use, sharing, adaptation, distribution and reproduction in any medium or format, as long as you give 
appropriate credit to the original author(s) and the source, provide a link to the Creative Commons licence, and indicate if changes were made. The images or other third party material in this article are included in the article's Creative Commons licence, unless indicated otherwise in a credit line to the material. If material is not included in the article's Creative Commons licence and your intended use is not permitted by statutory regulation or exceeds the permitted use, you will need to obtain permission directly from the copyright holder. To view a copy of this licence, visit http://creativecommons.org/licenses/by/4.0/.

\section{References}

Bealer, G. (1998). A theory of concepts and concept possession. Philosophical Issues, 9, 261-301.

Bengson, J., \& Moffett, M. (2011). Nonpropositional intellectualism. In Knowing how: Essays on knowledge, mind, and action. Oxford: Oxford University Press.

Boghossian, P. (2003). Blind reasoning. Aristotelian Society Supplementary, 77, 225-248.

Carroll, L. (1895). What the tortoise said to achilles. Mind, 4(14), 278-280.

Carter, J. A. (2017). Virtuous insightfulness. Episteme, 14(4), 539-554.

Chow, B., Lu, P., \& Ni, L. (2006). Hamilton's Ricci flow. Philadelphia: American Mathematical Society.

Collins, J. (2018). The redundancy of the act. Synthese, 195(8), 3519-3545.

Duncan, M. (2018). Propositions are not simple. Philosophy and Phenomenological Research, 97(2), $351-366$.

Eklund, M. (2019). Regress, unity, facts, and propositions. Synthese, 196(4), 1225-1247.

Elgin, C. (2009). Is understanding factive? In A. Haddock, A Millar \& D. Pritchard (Eds.), Oxford: Oxford University Press.

Evans, G. (1982). The varieties of reference. Oxford: Oxford University Press.

Faulkner, P. (2003). Good knowledge, bad knowledge. Mind, 112(446), 346-349. https://doi.org/10.1093/ mind/112.446.346.

Fricker, E. (2003). Understanding and knowledge of what is said. In A. Barber (Ed.), Epistemology of language (pp. 325-366). Oxford: Oxford University Press.

Garcia-Carpintero, M. (ms). Pretence, cancellation, and the act theory of propositions.

Garcia-Carpintero, M., \& Jespersen, B. (2019). Introduction: Primitivism versus reductionism about the problem of the unity of the proposition. Synthese, 196(4), 1209-1224.

Gaskin, R. (2008). The unity of the proposition. Oxford: Oxford University Press.

Ginet, C. (2010). Reply to Hetherington. Veritas (Porto Alegre), 55(2), 18-23.

Gordon, E. C. (2017). Understanding in epistemology. Internet Encyclopedia of Philosophy. https://iep. utm.edu/understa/.

Greco, J. (2014). Episteme: Knowledge and understanding. In K. Timpe, C. A. Boyd (Eds.), Oxford: Oxford University Press.

Grimm, S. R. (2006). Is understanding a species of knowledge? The British Journal for the Philosophy of Science, 57(3), 515-535.

Grimm, S. R. (2011). Understanding. In D. Pritchard \& S. Bernecker (Eds.), The Routledge companion to epistemology. London: Routledge.

Grimm, S. (2012). The value of understanding. Philosophy Compass, 7(2), 103-117. https://doi.org/10.11 11/j.1747-9991.2011.00460.x.

Grimm, S. R. (2014). Understanding as knowledge of causes. In Virtue epistemology naturalized (pp. 329-345). Berlin: Springer.

Grodniewicz, J. P. (ms). The representational structure of linguistic understanding.

Grodniewicz, J. P. (2020). The process of linguistic understanding. Synthese. https://doi.org/10.1007/s112 29-020-02807-9.

Grzankowski, A., \& Buchanan, R. (2019). Propositions on the cheap. Philosophical Studies, 176(12), 3159-3178.

Heck, R. G. (1995). The sense of communication. Mind, 104(413), 79-106.

Hetherington, S. (2001). Good knowledge, bad knowledge: On two dogmas of epistemology. Oxford: Clarendon Press.

Hetherington, S. (2011). How to know: A practicalist conception of knowledge. New York: Wiley.

Hetherington, S. (2013). Concessive knowledge-attributions: Fallibilism and gradualism. Synthese, 190(14), 2835-2851. 
Hills, A. (2009). Moral testimony and moral epistemology. Ethics, 120(1), 94-127.

Hills, A. (2016). Understanding why. Nô̂s, 50(4), 661-688.

Hunter, D. (1998). Understanding and belief. Philosophical and Phenomenological Research, 559-580.

Kelp, C. (2015). Understanding phenomena. Synthese, 192(12), 3799-3816.

Kelp, C. (2016). Towards a knowledge-based account of understanding. In S. Grimm, C. Baumberger, \& S. Ammon (Eds.), Explaining understanding. London: Routledge.

Khalifa, K. (2013). Is understanding explanatory or objectual? Synthese, 190(6), 1153-1171.

King, J. C. (2019). Structured propositions. In E. N. Zalta (Ed.), The Stanford encyclopedia of philosophy. Stanford: Metaphysics Research Lab, Stanford University.

Kvanvig, J. (2003). The value of knowledge and the pursuit of understanding. Cambridge: Cambridge University Press.

Kvanvig, J. L. (2013). Curiosity and a response-dependent account of the value of understanding. In T. Henning, \& D. Schweikard (Eds.), Knowledge, virtue, and action Boston: Routledge.

Kvanvig, J. L. (2017). Understanding. In F. Aquino, \& D. Abraham (Eds.), Oxford handbook on the epistemology of theology. Oxford: Oxford University Press.

Leite, A. (2006). Epistemic gradualism and ordinary epistemic practice: Responce to hetherington. Philosophia, 34(3), 311-324.

Longworth, G. (2018). Understanding what was said. Synthese, 195(2), 815-834.

Mandelbaum, E. (2014). Thinking is believing. Inquiry, 57(1), 55-96.

Millar, A. (1994). Possessing concepts. Mind, 103(409), 73.

Millikan, R. G. (2004). Varieties of meaning: The 2002 Jean Nicod lectures. Cambridge: MIT Press.

Pavese, C. (2015). Knowing a rule. Philosophical Issues, 25(1), 165-188.

Pavese, C. (2017). Know-how and gradability. The Philosophical Review, 126(3), 345-383.

Peacocke, C. (1989). Possession conditions: A focal point for theories of concepts. Mind and Language, $4(1-2), 51-56$.

Perelman, G. (2002). The entropy formula for the Ricci flow and its geometric applications. arXiv Preprint Math/0211159.

Pritchard, D. (2005). Epistemic luck. Oxford: Oxford University Press.

Pritchard, D. (2009). Knolwedge, understanding and epistemic value. Royal Institute of Philosophy Supplement, 64, 19-43.

Pritchard, D. (2015). Anti-luck epistemology and the gettier problem. Philosophical Studies, 172(1), 93-111.

Riggs, W. D. (2003). Understanding 'Virtue' and the virtue of understanding. In M. DePaul \& L. Zagzebski (Eds.), Intellectual virtue: Perspectives from ethics and epistemology (pp. 203-226). Oxford: Oxford University Press.

Riggs, W. D. (2009). Understanding, knowledge, and the meno requirement. In A. Haddock, A. Millar, \& D. Pritchard (Eds.), Epistemic value. Oxford: Oxford University Press.

Ryle, G. (1945). Knowing how and knowing that: The presidential address. In Proceedings of the Aristotelian Society (pp. 1-16). JSTOR.

Zagzebski, L. (2001). Recovering understanding. In M. Steup (Ed.), Knowledge, truth, and duty: Essays on epistemic justification, responsibility, and virtue. Oxford: Oxford University Press.

Publisher's Note Springer Nature remains neutral with regard to jurisdictional claims in published maps and institutional affiliations. 